\title{
Correction of Toxic Liver Damage with a Multicomponent Herbal Extract in an Animal Experiment
}

\author{
Ferubko EV' ${ }^{1}$ Nikolaev SM², Dargaeva TD ${ }^{1}$, Rendyuk TD ${ }^{3, *}$
}

Ferubko EV', Nikolaev SM², Dargaeva TD ${ }^{1}$, Rendyuk TD ${ }^{3, *}$

'All-Russian Research Institute of Medicinal and Aromatic Plants, Moscow, RUSSIA. ${ }^{2}$ Institute of General and Experimental Biology of the Siberian Branch of the RAS, Ulan-Ude, RUSSIA.

${ }^{3}$ Sechenov First Moscow State Medical University, Moscow, RUSSIA.

\section{Correspondence}

\section{Rendyuk TD}

Sechenov First Moscow State Medical University, Moscow, RUSSIA

E-mail: aramat_17@mail.ru

History

- Submission Date: 14-10-2019;

- Review completed: 30-10-2019;

- Accepted Date: 14-11-2019.

DOI : 10.5530/pj.2020.12.25

Article Available online

http://www.phcogj.com/v12/i1

\section{Copyright}

(c) 2020 Phcogi.Com. This is an openaccess article distributed under the terms of the Creative Commons Attribution 4.0 International license.

\section{ABSTRACT}

Background: Digestive diseases constitute a significant part in the overall structure of human diseases. Herbal cholagogues are indicated for a treatment of chronic liver, gall bladder, and bile ducts diseases. The aim of the work is to determine the choleretic effect of a new multicomponent plant extract. Materials and Methods: Multicomponent plant extract was obtained from the following types of plant materials: $300 \mathrm{~g}$ of immortelle flowers (Helichrysum arenarium L.), $100 \mathrm{~g}$ of tansy flowers (Tanacetum vulgare L.), $100 \mathrm{~g}$ of rose fruits (Rosa sp.), $100 \mathrm{~g}$ of leaves of common nettle (Urtica dioica L.), $50 \mathrm{~g}$ of mint leaves (Mentha piperita L.), $50 \mathrm{~g}$ of licorice roots (Glycyrrhiza glabra L.). The extract was standardized by the total flavonoid content. It was calculated and expressed in terms of luteolin and isosalipurposide standards (total flavonoids content: not less than $4 \%$ and $15 \%$ respectively). The animal experiments being done in 80 nonlinear male rats with initial body weight $180-200 \mathrm{~g}$. In order to study a choleretic effect of multicomponent herbal extract, naive rats recieved the single experimental dose of $250 \mathrm{mg} / \mathrm{kg}$. Pharmacotherapeutic activity was studied in white rats with $\mathrm{CCl}_{4}$-induced hepatitis. Results: Studies indicate a pronounced choleretic effect of the studied plant extract, that is comparable with the effect of "Allochol" in intact rats experiments. The course administration of a per os (peroral) multicomponent plant extract in a dose of $250 \mathrm{mg} / \mathrm{kg}$ to white non-linear rats with tetrachloromethane liver damage has a choleretic effect: it increases the rate of bile secretion, stimulates the synthesis and secretion of cholates with bile, and also the excretion of cholesterol and bilirubin. Conclusion: The obtained research results argue the feasibility of using a multicomponent plant extract containing biologically active substances of phenolic nature in the prevention and comprehensive treatment of liver diseases.

Key words: Multicomponent extract, Choleretic effect, Experimental hepatitis.

\section{INTRODUCTION}

Digestive diseases constitute a significant part in the overall structure of human diseases. This diseases category is characterized by a relapsing course, functional disorders in the case of organic nature of disease. ${ }^{1,2}$

Herbal cholagogues are indicated for a treatment of chronic liver, gall bladder, and bile ducts diseases. ${ }^{3}$ A range of herbal drugs with choleretic activity is not wide and includes species, tablets containing purified extracts of "Flamin" (Helichrysi arenarii floridis flavonoids), "Caleflonum" (Calendulae officinalis floridis extract) and "Chophytol" (Cynarae scomuli foliae extract), Chophytol oral solution, "Allochol" tablets et al. ${ }^{4}$

In view of this, the expansion of the list of herbal drugs with choleretic activity is a promising way. Within this framework, it is reasonable to create new effective plant-based medicines. ${ }^{5-7}$

As is well known, phytopreparations have a mild, moderate and natural (physiological) effect on the body, have a gradually, but steadily developing therapeutic effect, unlike synthetic drugs. Herbal remedies have a small number of contraindications or practically do not have them. When taking herbal remedies, side effects, cases of intolerance are observed relatively rarely.
From this perspective, the purpose of our study was determining the choleretic activity of multicomponent plant extract.

\section{MATERIALS AND METHODS}

Based on the literary analysis and data collected from a preliminary phytochemical study of plant material, the components of extract were substantiated including the contribution of every ingredient. ${ }^{8-11}$

The object of study was dry extract from plant material: $300 \mathrm{~g}$ of immortelle flowers (Helichrysum arenarium L.); $100 \mathrm{~g}$ of tansy flowers (Tanacetum vulgare L.); $100 \mathrm{~g}$ of rose fruits (Rosa sp. - Rosa majalis Herrn., Rosa acicularis Undl., Rosa canina L. and others); $100 \mathrm{~g}$ of leaves of common nettle (Urtica dioica L.); $50 \mathrm{~g}$ of mint leaves (Mentha piperita L.); 50 g of licorice roots (Glycyrrhiza glabra L.).

The components mixture was extracted with hot water $\left(75-85^{\circ} \mathrm{C}\right)$. The resulting extract contained polysaccharides, flavonoids, carotenoids, organic acids, vitamins, macro-and microelements, essential oils, and other natural compounds. The total flavonoid content was calculated and expressed in terms of luteolin and isosalipurposide standards (total flavonoids content: not less than $4 \%$ and $15 \%$ respectively). This biologically active substances are known for potential choleretic activity of the extract.

Cite this article: Ferubko EV, Nikolaev SM, Dargaeva TD, Rendyuk TD. Correction of Toxic Liver Damage with a Multicomponent Herbal Extract in an Animal Experiment. Pharmacog J. 2020;12(1):168-72. 
The study was carried out in accordance with the Russian Federations's Federal Law "On Circulation of Medicines", "Guidelines for Preclinical Trials of Medicinal Products". The experiments being done in 80 nonlinear male rats with initial body weight 180-200 g. Animals were received from Federal State-Funded Institution of Science "Scientific Centre of Biomedical Technologies" of Federal Medical and Biological Agency of Russia and kept in animal facility with free access to food and water. Pharmacological research was carried out in compliance with the Order of the Ministry of Health of the Russian Federation No. 199n of April 01, 2016 "On Approval of Rules of Good Laboratory Practice" and in accordance with GLP. ${ }^{12}$ The studies were approved by local Bioethics Committee (Protocol No. 7 of October 01, 2018).

In order to study a choleretic effect of multicomponent herbal extract, naive rats recieved the single experimental dose of $250 \mathrm{mg} / \mathrm{kg}$. "Allochol" (a herbal cholagogue) registered in Russian State Register of Medicinal Remedies was chosen as a standard medication at dose of $250 \mathrm{mg} / \mathrm{kg}$.

Bile samples were taken from anesthetized animal (thiopental sodium, $45 \mathrm{mg} / \mathrm{kg}$ ) through polyethylene cannula inserted into the common bile duct. The samples were collected every hour during 4 hours. The cholagogue activity of the extract was measured by the speed of secretion and the quantity of the total excreted bile, and also by the levels of bilirubin, bile acids, and cholesterol.

Pharmacotherapeutic activity was studied in white rats with $\mathrm{CCl}_{4-}^{-}$ induced hepatitis. The water extract was given intragastrically at a dose of $250 \mathrm{mg} / \mathrm{kg}$ per day during 10 days starting from day 2 after impairing agent exposure. Liver damage was inducted by intragastric administration of $50 \%$ oil solution of tetrachloromethane $(0,4 \mathrm{ml} / 100$ g body weight per day during 4 days..$^{13}$ Control group received an appropriate amount of purified water on a similar basis. A measure of activity was performed on days 7, 14, 21, and 28 of experiment.

Statistical data processing was done by using Statistica software program version 6.0 (USA). ${ }^{14}$ Differences were considered statically significant at $P \leq 0,05$.

\section{RESULTS AND DISCUSSION}

Pharmacological study of choleretic activity of the resulting extract compared to "Allochol" was carried out in intact white rats. The results are shown in the Tables 1-5.
From the results given in Table 1, it can be seen that the herbal extract at a specified dose has a stronger choleretic activity than "Allochol". Receiving the extract, the increase of bile excretion in white rats appeared quickly and lasted for 4-5 hours, while receiving "Allochol" the effect lasted for 3-4 hours.

We researched the effect of the extract and "Allochol" on the amount of excreted bile for 2-5 hours in the experiment. It was established that receiving the extract the amount of bile excreted increased in the midst of intense bile excretion. "Allochol" had a lower choleretic effect.

This appearing effect in rats is accompanied by changes in the levels of major bile components - bile acids, cholesterol and bilirubin. The levels of bile acids, cholesterol and bilirubin in the bile excreted increased after extract administration. Given the herbal extract white rats with toxic hepatitis had an increased bile excretion rate.

The achieved results indicate a significant effect of the studied extract on the choleretic activity in white rats with induced liver damage. So, on Day 7 the rate of bile excretion increased, on average, by $46 \%$, compared with the control group (Table 6). On Day 14 the rate of bile excretion increased by $41,5 \%$, Day $21-44 \%$, and Day $28-38 \%$ (from hour 2 to 4).

The analysis of the bile composition showed an increase of bile acids, bilirubin and cholesterol under the influence of the studied extract.

Cholates level increased 2.5 times, 1.5 times, 2 times on Day 7-21 of the experiment. While white rats were receiving the studied extract, bile bilirubin excretion increased 2.3 times on Day 7, 1.5 times on Day 14-21 in comparison with control group. Amount of bile cholesterol increased by 50,18 and $12 \%$ on Day 7,14 and 21 respectively in comparison with control group (Table 7). Multicomponent herbal extract represses bile formation and excretion at early stages of liver damage. These positive changes lead to reduce the severity of pathological process.

It was established that per os administration of the extract at dose of $250 \mathrm{mg} / \mathrm{kg}$ during the course produce choleretic effect in white rats with $\mathrm{CCl}_{4}$-induced liver damage. Effect of the extract precedes an effect of "Allochol" in a number of indicators. The presence of biologically active substances (particularly phenolics) induces a choleretic effect and subsequent increase of liver capacity. ${ }^{15-22}$

\section{Table 1: The effect of multicomponent herbal extract on the rate of bile secretion in intact rats.}

\begin{tabular}{|c|c|c|c|c|c|c|c|c|}
\hline \multirow{2}{*}{ № } & \multirow{2}{*}{ Drug name } & \multirow{2}{*}{ Dose, mg/kg } & \multicolumn{6}{|c|}{ Rate of bile secretion $(\mathrm{mg} / \mathrm{min}$ per $100,0 \mathrm{~g})$} \\
\hline & & & $1 \mathrm{~h}$. & $2 \mathrm{~h}$. & $3 \mathrm{~h}$. & $4 \mathrm{~h}$. & $5 \mathrm{~h}$. & $6 \mathrm{~h}$. \\
\hline 1. & $\begin{array}{l}\text { Distilled water } \\
\text { (control) }\end{array}$ & - & $2,6 \pm 0,2$ & $2,8 \pm 0,1$ & $2,5 \pm 0,1$ & $2,7 \pm 0,2$ & $2,2 \pm 0,2$ & $1,8 \pm 0,2$ \\
\hline 2. & Herbal extract & 250 & $2,6 \pm 0,3^{*}$ & $5,0 \pm 0,4^{*}$ & $5,0 \pm 0,3^{*}$ & $4,2 \pm 0,2^{*}$ & $3,2 \pm 0,2^{*}$ & $2,5 \pm 0,1^{*}$ \\
\hline 3. & "Allochol" & 250 & $2,7 \pm 0,2^{*}$ & $4,1 \pm 0,3^{*}$ & $4,3 \pm 0,2^{*}$ & $3,8 \pm 0,3^{*}$ & $2,9 \pm 0,4^{*}$ & $2,2 \pm 0,2$ \\
\hline
\end{tabular}

Note: Here and elsewhere below asterisk ${ }^{*}$ denote significant differences at $P<0,05$.

Table 2: Effect of a complex extract on the amount of bile excreted during hours 2-5 of the experiment in intact rats.

\begin{tabular}{|c|c|c|c|c|c|c|c|}
\hline \multirow{2}{*}{ № } & \multirow{2}{*}{ Drug name } & \multirow{2}{*}{ Dose, $\mathrm{mg} / \mathrm{kg}$} & \multicolumn{4}{|c|}{ Amount of bile excreted, $\mathrm{mg} / 100 \mathrm{~g}$} & \multirow{2}{*}{$\begin{array}{l}\text { Total amount of bile excreted during } 4 \text { hours, } \\
\mathrm{mg} / 100 \mathrm{~g}\end{array}$} \\
\hline & & & $2 \mathrm{~h}$. & $3 \mathrm{~h}$. & $4 \mathrm{~h}$. & $5 \mathrm{~h}$. & \\
\hline 1. & Distilled water (control) & - & 168 & 150 & 162 & 132 & 612 \\
\hline 2. & Herbal extract & 250 & 300 & 300 & 252 & 192 & 1044 \\
\hline 3. & "Allochol" & 250 & 246 & 258 & 228 & 174 & 906 \\
\hline
\end{tabular}

Table 3: Effect of a multicomponent herbal extract and "Allochol" on the bile acids levels in intact rats.

\begin{tabular}{|c|c|c|c|c|c|c|c|}
\hline \multirow{2}{*}{ № } & \multirow{2}{*}{ Drug name } & \multirow{2}{*}{ Dose, $\mathrm{mg} / \mathrm{kg}$} & \multicolumn{4}{|c|}{ Amount of bile acids within 1 hour, $\mathrm{mg} / 100 \mathrm{~g}$} & \multirow{2}{*}{$\begin{array}{l}\text { Total amount of bile acids during } 4 \text { hours, } \\
\mathrm{mg} / 100 \mathrm{~g}\end{array}$} \\
\hline & & & $2 \mathrm{~h}$. & $3 \mathrm{~h}$. & $4 \mathrm{~h}$. & $5 \mathrm{~h}$. & \\
\hline 1. & Distilled water (control) & - & 1,51 & 1,23 & 1,30 & 1,01 & 5,05 \\
\hline 2. & Herbal extract & 250 & 3,09 & 2,76 & 2,14 & 1,54 & 9,53 \\
\hline 3. & "Allochol" & 250 & 2,58 & 2,37 & 1,94 & 1,40 & 8,29 \\
\hline
\end{tabular}


Table 4: Effect of a multicomponent herbal extract and "Allochol" on the bile cholesterol levels in intact rats.

\begin{tabular}{|c|c|c|c|c|c|c|c|}
\hline \multirow{2}{*}{ № } & \multirow{2}{*}{ Drug name } & \multirow{2}{*}{ Dose, $\mathrm{mg} / \mathrm{kg}$} & \multicolumn{4}{|c|}{ Amount of cholesterol within 1 hour, $\mathrm{mg} / 100,0 \mathrm{~g}$} & \multirow{2}{*}{$\begin{array}{c}\text { Total amount of cholesterol during } \\
4 \text { hours, } \mathrm{mg} / 100,0 \mathrm{~g}\end{array}$} \\
\hline & & & $2 \mathrm{~h}$. & $3 \mathrm{~h}$. & $4 \mathrm{~h}$. & $5 \mathrm{~h}$. & \\
\hline 1. & Distilled water (control) & - & 0,020 & 0,016 & 0,019 & 0,011 & 0,066 \\
\hline 2. & Herbal extract & 250 & 0,036 & 0,042 & 0,045 & 0,023 & 0,146 \\
\hline 3. & "Allochol" & 250 & 0,044 & 0,036 & 0,027 & 0,015 & 0,122 \\
\hline
\end{tabular}

Table 5: Effect of a multicomponent herbal extract and "Allochol" on the bile bilirubin levels in intact rats.

\begin{tabular}{|c|c|c|c|c|c|c|c|}
\hline \multirow{2}{*}{ № } & \multirow{2}{*}{ Drug name } & \multirow{2}{*}{ Dose, $\mathrm{mg} / \mathrm{kg}$} & \multicolumn{4}{|c|}{ Amount of bilirubin within 1 hour, $\mathrm{mg} / 100,0 \mathrm{~g}$} & \multirow{2}{*}{$\begin{array}{l}\text { Total amount of bilirubin } \\
\text { during } 4 \text { hours, } \mathrm{mg} / 100,0 \mathrm{~g}\end{array}$} \\
\hline & & & $2 \mathrm{~h}$. & $3 \mathrm{~h}$. & $4 \mathrm{~h}$. & $5 \mathrm{~h}$. & \\
\hline 1. & $\begin{array}{l}\text { Distilled water } \\
\quad \text { (control) }\end{array}$ & - & 0,018 & 0,015 & 0,015 & 0,013 & 0,061 \\
\hline 2. & Herbal extract & 250 & 0,033 & 0,030 & 0,030 & 0,023 & 0,116 \\
\hline 3. & "Allochol" & 250 & 0,027 & 0,025 & 0,026 & 0,017 & 0,095 \\
\hline
\end{tabular}

Table 6: Bile excretion rate dynamics under effect of a multicomponent extract in white rats with experimental hepatitis induced by $\mathrm{CCl}_{4}$.

\begin{tabular}{|c|c|c|c|c|}
\hline \multirow{2}{*}{ Experimental conditions } & \multicolumn{4}{|c|}{ Bile excretion rate during 4 hours, $\mathrm{mg} / \mathrm{min}$ per $100 \mathrm{~g}$ of body weight } \\
\hline & 1 hour & 2 hours & 3 hours & 4 hours \\
\hline \multirow[t]{2}{*}{ Intact rats } & $5,4 \pm 0,3$ & $5,2 \pm 0,2$ & $5,2 \pm 0,4$ & $5,2 \pm 0,4$ \\
\hline & \multicolumn{3}{|c|}{ Day 7} & \\
\hline Control rats $\left(\mathrm{CCl}_{4}+\mathrm{H}_{2} \mathrm{O}\right)$ & $3,7, \pm 0,3$ & $3,2 \pm 0,3$ & $2,9 \pm 0,2$ & $2,6 \pm 0,2$ \\
\hline $\begin{array}{l}\text { Experimental rats } \\
\left(\mathrm{CCl}_{4}+\text { an extract }\right)\end{array}$ & $5,3 \pm 0,2^{\star *}$ & $5,0 \pm 0,3^{* *}$ & $4,1 \pm 0,4^{\star}$ & $3,8 \pm 0,3^{* *}$ \\
\hline \multirow[t]{2}{*}{$\begin{array}{l}\text { Experimental rats } \\
\left(\mathrm{CCl}_{4}+\text { "Allochol") }\right.\end{array}$} & $5,2 \pm 0,3^{*}$ & $4,8 \pm 0,2^{*}$ & $4,0 \pm 0,3$ & $4,3 \pm 0,2^{*}$ \\
\hline & \multicolumn{3}{|c|}{ Day 14} & \\
\hline Control rats $\left(\mathrm{CCl}_{4}+\mathrm{H}_{2} \mathrm{O}\right)$ & $4,4 \pm 0,4$ & $4,4 \pm 0,3$ & $4,3 \pm 0,3$ & $4,0 \pm 0,4$ \\
\hline $\begin{array}{l}\text { Experimental rats } \\
\left(\mathrm{CCl}_{4}+\text { an extract }\right)\end{array}$ & $6,0 \pm 0,5^{*}$ & $5,8 \pm 0,4^{*}$ & $6,2 \pm 0,3^{\star *}$ & $6,2 \pm 0,2^{* *}$ \\
\hline \multirow[t]{2}{*}{$\begin{array}{l}\text { Experimental rats } \\
\left(\mathrm{CCl}_{4}+\text { "Allochol") }\right.\end{array}$} & $5,8 \pm 0,4$ & $5,6 \pm 0,3^{*}$ & $5,8 \pm 0,4$ & $5,8 \pm 0,3$ \\
\hline & \multicolumn{3}{|c|}{ Day 21} & \\
\hline Control rats $\left(\mathrm{CCl}_{4}+\mathrm{H}_{2} \mathrm{O}\right)$ & $4,3 \pm 0,1$ & $4,0 \pm 0,2$ & $4,5 \pm 0,2$ & $3,9 \pm 0,2$ \\
\hline $\begin{array}{c}\text { Experimental rats } \\
\left(\mathrm{CCl}_{4}+\text { an extract }\right)\end{array}$ & $6,6 \pm 0,3^{* *}$ & $6,0 \pm 0,5^{\star *}$ & $5,8 \pm 0,4^{*}$ & $5,6 \pm 0,5^{* *}$ \\
\hline \multirow[t]{2}{*}{$\begin{array}{l}\text { Experimental rats } \\
\left(\mathrm{CCl}_{4}+\text { "Allochol") }\right.\end{array}$} & $6,2 \pm 0,2^{\star}$ & $5,7 \pm 0,4$ & $5,5 \pm 0,3^{*}$ & $5,3 \pm 0,3^{\star}$ \\
\hline & \multicolumn{3}{|c|}{ Day 28} & \\
\hline Control rats $\left(\mathrm{CCl}_{4}+\mathrm{H}_{2} \mathrm{O}\right)$ & $4,7 \pm 0,4$ & $4,4 \pm 0,4$ & $4,4 \pm 0,4$ & $3,3 \pm 0,3$ \\
\hline $\begin{array}{l}\text { Experimental rats } \\
\left(\mathrm{CCl}_{4}+\text { an extract }\right)\end{array}$ & $4,8 \pm 0,2$ & $5,5 \pm 0,1^{\star}$ & $5,6 \pm 0,3^{* *}$ & $5,0 \pm 0,1^{\star *}$ \\
\hline $\begin{array}{l}\text { Experimental rats } \\
\left(\mathrm{CCl}_{4}+\text { "Allochol") }\right.\end{array}$ & $4,5 \pm 0,2$ & $5,2 \pm 0,2^{*}$ & $5,3 \pm 0,3^{*}$ & $4,7 \pm 0,2^{*}$ \\
\hline
\end{tabular}

Note: Here and elsewhere below asterisk ${ }^{\star}$ denote that the differences between control and experimental groups are significant at $P<0,05$ : asterisks ${ }^{\star}$ denote that the differences between control and experimental groups are significant at $P<0,01$. 
Table 7: Bile composition dynamics under the influence of multicomponent herbal extract in white rats with experimental hepatitis induced by $\mathrm{CCl}_{4}$.

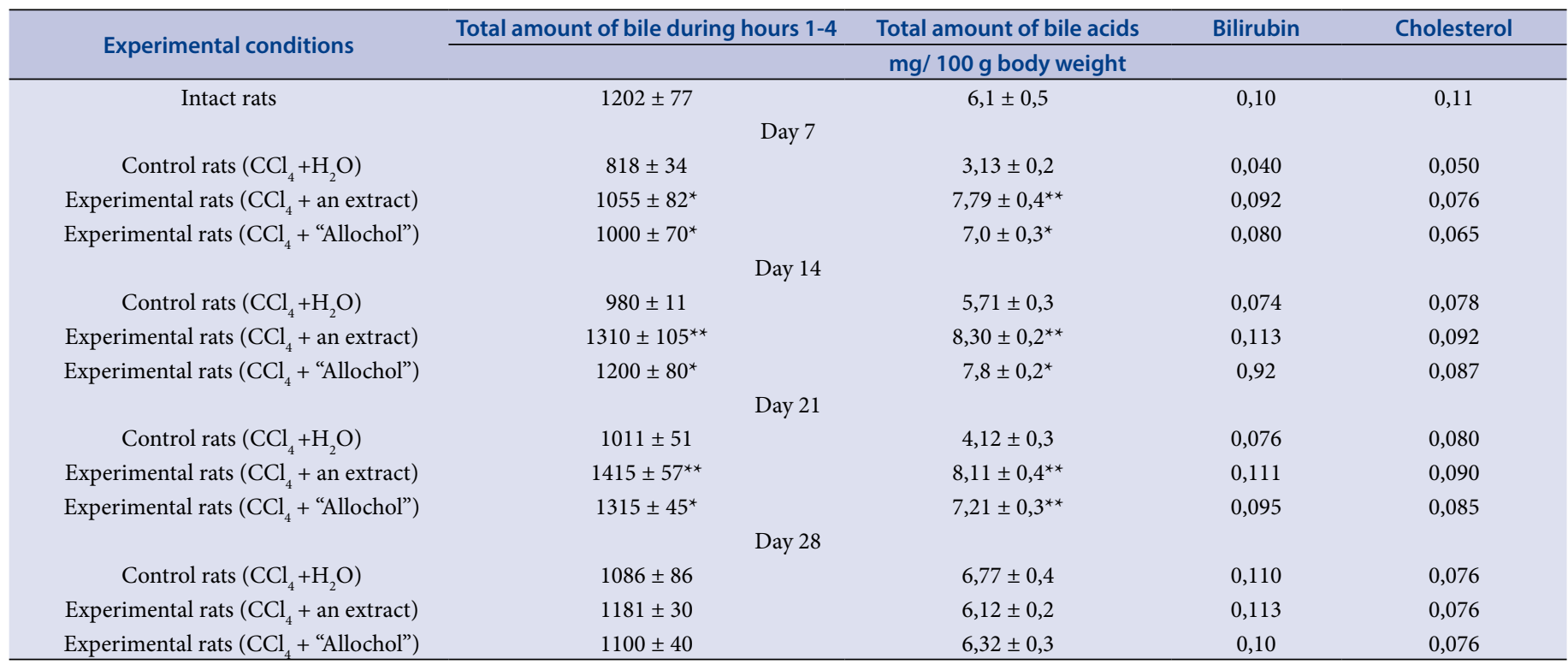

\section{CONCLUSION}

Altogether, these data demonstrate a significant choleretic effect of a herbal extract, which is comparable to effect of "Allochol" in experiment in intact rats. Per os administration of the extract at dose of $250 \mathrm{mg} /$ $\mathrm{kg}$ during the course produce choleretic effect in white rats with $\mathrm{CCl}_{4}$ induced liver damage. The extract increases the rate of bile excretion, stimulates synthesis and excretion of the cholates, and also induces excretion of cholesterol and bilirubin. The given results prove that it is reasonable to use the multicomponent herbal extract containing biologically active substances of phenolic nature for combined therapy and preventive care of hepatobiliary system diseases.

\section{ACKNOWLEDGMENT}

This paper was financially supported by "Russian Academic Excellence Project 5-100".

\section{CONFLICTS OF INTEREST}

None.

\section{REFERENCES}

1. Zhang $A$, Sun $H$, Wang $X$. Recent advances in natural products from plants for treatment of liver diseases. Eur J Med Chem. 2013;63:570-7.

2. Zimmerman YaS. Unresolved and controversial problems of modern gastroenterology. Moscow: MEDpress-inform 2013;224

3. Hirschfield GM, Heathcote EJ, Gershwin ME. Pathogenesis of cholestatic liver disease and therapeutic approaches. Gastroenterology. 2010;139:1481-96.

4. State Register of medicines of the Russian Federation. URL: https:// grls.rosminzdrav.ru/ [cited 2019 Jun 7].

5. Lubsandorzhieva P. -N.B. Development and standardization of herbal remedies for the treatment and prevention of digestive diseases. Ulan-Ude: Publishing House of the BSC SB RAS, 2016;280 [in Russian].

6. Samani MA, Kafash-Farkhad N, Azimi N. Medicinal plants with hepatoprotective activity in Iranian folk medicine. Asian Pac J Trop Biomed. 2015;5:146-57.

7. Valero A, Romero MC, Gomez-Mateos M, Hierro I, Navarro MC. Natural products: perspectives in the pharmacological treatment in gastrointestinal anisakiasis. Asian Pac J Trop Biomed. 2015;8: 612-7.

8. Madrigal-Santillán E, Madrigal-Bujaidar E, Álvarez-González I, SumayaMartínez MT, Gutiérrez-Salinas J, Bautista M, et al. Review of natural products with hepatoprotective effects. World J Gastroenterol. 2014;20:14787-804.

9. Mehta P, Shah R, Lohidasan S, Mahadik KR. Pharmacokinetic profile of phytoconstituent(s) isolated from medicinal plants - a comprehensive review. Journal of J Tradit Complement Med. 2015;5:207-27.

10. Joshi BC, Mukhija M, Kalia AN. Pharmacognostical review of Urtica dioica L. Int J Green Pharm. 2014;8:201-9.

11. Singh R, Shushi MAM, Belkheir A. Antibacterial and antioxidant activities of Mentha piperita L. Arab J Chem. 2015;8:322-8.

12. Image reproduced from ICH. M4: The Common Technical Document Retrieved 25 June, 2015, URL: http://www.ich.org/products/ctd.html [cited 2019 Jun 9].

13. Khabriev RU. Guidance on the experimental (preclinical) study of new pharmacological substances. Moscow: Medicine 2012;832 [in Russian]

14. Borovikov VP. A popular introduction to modern data analysis in the STATISTICA system, Moscow: Hot line. Telecom. 2014;288 [in Russian].

15. Nikolaev SM. Phytopharmacotherapy and phytopharmacoprophylaxis of diseases. Ulan-Ude: Publishing House of BSU; 2012,286 [in Russian].

16. Korsun VF, Nikolaev SM, Ogrenich MA, Korsun EV, Bartanova EA Sultanbekov BA. Medicinal plants and liver diseases: a guide to clinical herbal medicine. Moscow: Practical medicine; 2014;327 [in Russian].

17. Kumar S Pandey AK. Chemistry and biological activities of flavonoids: An review [Electronic resource]. The Scientific World Journal 2013. URL: http://dx.doi.org/10.1155/2019/162750 [cited 2019 Jun 9].

18. Jadeja RN, Devkar RV. Polyphenols and flavonoids in controlling nonalcoholic steatohepatitis. Polyphenols in Human Health and Disease. 2014;1:615-23.

19. González-Gallego J, García-Mediavilla MV, Sánchez-Campos S, Tuñón MJ. Anti-inflammatory and immunomodulatory properties of dietary flavonoids. Polyphenols in Human Health and Disease. 2014;1(32):435-52.

20. Ambriz-Perez DL, Leyva-Lopez N, Gutierrer-Grijalva EP, Heredia JB. Phenolic compounds: natural alternative in inflammation treatment, $A$ review. Cogent Food Agric. 2016;2:1-14.

21. Agrawal AD. Pharmacological activities of flavonoids: a review. Int J Pharm Sci Nanotechnol. 2011;4:1394-8

22. Unnikrishnan MK, Veerapur V, Nayak Y, Mudgal PP, Mathew G. Antidiabetic, antihyperlipidemic and antioxidant effects of the flavonoids. Polyphenols in Human Health and Disease. 2014;1 (13):143-61. 


\section{GRAPHICAL ABSTRACT}

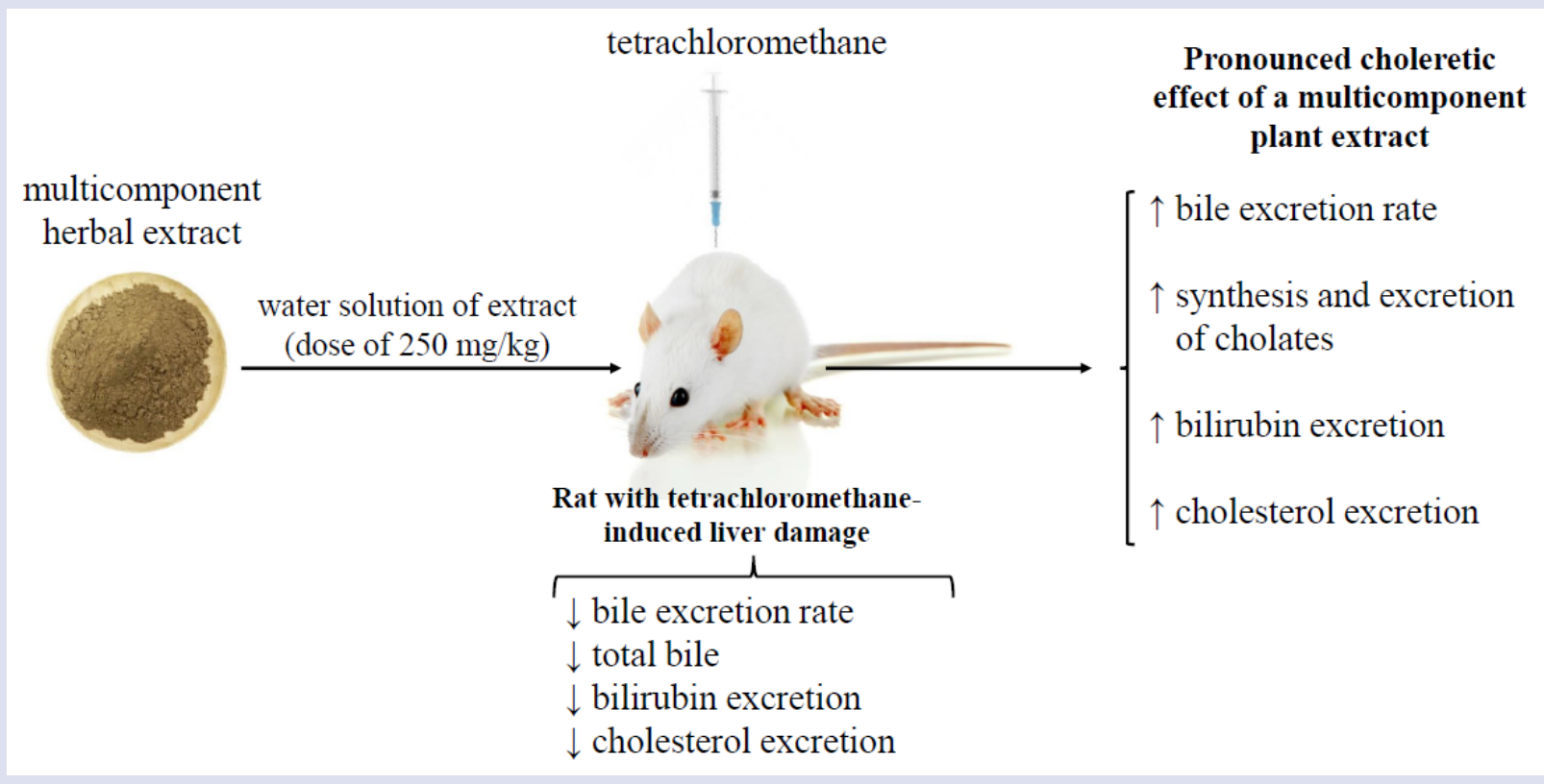

\section{ABOUT AUTHORS}

- Ferubko Ekaterina Vladimirovna: Candidate of Medical Sciences, Head of the Department of Experimental and Clinical Pharmacology, All-Russian Scientific Research Institute of Medicinal and Aromatic Plants (Russia, Moscow). Research interests: study of targeted pharmacological activity and interpretation of the mechanism of action of promising herbal medicines.

- Nikolaev Sergey Matveevich: Doctor of Medical Sciences, professor, chief researcher at the Laboratory of Experimental Pharmacology of Institute of General and Experimental Biology of the Siberian Branch of the RAS (Russia, Ulan-Ude). Research interests: study of targeted pharmacological activity and interpretation of the mechanism of action of promising herbal medicines.

- Dargaeva Tamara Darizhapovna: Doctor of Pharmaceutical Sciences, professor, chief researcher at the Department of Phytochemistry and Standardization, All-Russian Research Institute of Medicinal and Aromatic Plants (Russia, Moscow). Research interests: search for promising sources of biologically active substances and the creation on their basis of highly effective herbal medicines.

- Rendyuk Tamara Danilovna: Candidate of Pharmaceutical Sciences, Associate Professor, Department of Pharmaceutical Natural Sciences, Institute of Pharmacy, Sechenov University (Russia, Moscow). Research interests: search for promising sources of biologically active substances and the creation on their basis of highly effective herbal medicines.

Cite this article: Ferubko EV, Nikolaev SM, Dargaeva TD, Rendyuk TD. Correction of Toxic Liver Damage with a Multicomponent Herbal Extract in an Animal Experiment. Pharmacog J. 2020;12(1):168-72. 